\title{
Inhalational Anesthetics as Preconditioning Agents in Ischemic Brain
}

\author{
Lan Wang, MD*, Richard J. Traystman, PhD, and Stephanie J. Murphy, VMDPhD \\ Oregon Health and Science University, Department of Anesthesiology and Peri-Operative Medicine, \\ 3181 SW Sam Jackson Road, Mail Code: UHS-2, Portland, OR 97239-3098
}

\section{SUMMARY}

While many pharmacological agents have been shown to protect the brain from cerebral ischemia in animal models, none have translated successfully to human patients. One potential clinical neuroprotective strategy in humans may involve increasing the brain's tolerance to ischemia by preischemic conditioning (preconditioning). There are many methods to induce tolerance via preconditioning such as: ischemia itself, pharmacological, hypoxia, endotoxin, and others. Inhalational anesthetic agents have also been shown to result in brain preconditioning. Mechanisms responsible for brain preconditioning are many, complex, and unclear and may involve Akt activation, ATP-sensitive potassium channels, and nitric oxide, amongst many others. Anesthetics, however, may play an important and unique role as preconditioning agents, particularly during the perioperative period.

\section{INTRODUCTION}

\begin{abstract}
Previous exposure of the brain to minor insults, chemicals, or pharmacological agents can "precondition" or increase the brain's tolerance to future, more injurious events. This acquired tolerance can be induced transiently and rapidly or in a delayed and sustained fashion, suggesting that multiple mechanisms may be involved. Virtually any stimulus used to induce brain injury or alter brain function can be applied in a milder form to potentially precondition the brain (Table 1). Inhalational anesthetic preconditioning is considered to be a type of chemical preconditioning in brain [1].
\end{abstract}

Anesthetic preconditioning of the brain during neurosurgical and cardiovascular surgeries may prevent or delay neurological complications like perioperative stroke. Perioperative stroke is a serious complication that can occur during or following procedures such as carotid endarterectomy (CEA), which has a reported perioperative stroke incidence from $0.25 \%$ to $7 \%$ [2,3]. According to the North American Symptomatic Carotid Endarterectomy Trial, 35\% and $65 \%$ of perioperative strokes occurred during or after CEA, respectively [4]. Approximately $56 \%$ of these post-procedural strokes occurred within 24 hours after CEA [4]. Studies evaluating volatile anesthetics may identify new and more medically feasible means of conditioning a brain that might be exposed to ischemic or mechanical injury from surgery and other interventional procedures.

Correspondence: Stephanie J. Murphy, VMD, PhD, Oregon Health and Science University, Department of Anesthesiology and PeriOperative Medicine, 3181 SW Sam Jackson Road, Mail Code: UHS-2, Portland, OR 97239-3098, Phone: (503) 494-5735, Fax: (503) 494-4588, E-mail: murphyst@ohsu.edu.

*Present affiliation: Department of Neurology at the Affiliated Drum Tower Hospital of Nanjing University, PR China.

Publisher's Disclaimer: This is a PDF file of an unedited manuscript that has been accepted for publication. As a service to our customers we are providing this early version of the manuscript. The manuscript will undergo copyediting, typesetting, and review of the resulting proof before it is published in its final citable form. Please note that during the production process errors may be discovered which could affect the content, and all legal disclaimers that apply to the journal pertain. 
This review will discuss the most recent research concerning inhalational anesthetic effects before (preconditioning) rather than during (neuroprotection) ischemic brain injury. Currently utilized models of volatile anesthetic preconditioning in ischemic brain will be described in terms of the types of inhalational anesthetics, ischemic models, and animal species used as well as length and frequency of preconditioning, intervals between preconditioning and cerebral ischemia, and outcomes. The preconditioning actions of isoflurane, sevoflurane, halothane, and xenon (Table 2) will be evaluated along with potential mechanisms underlying volatile anesthetic preconditioning effects. The role of gender and age on brain preconditioning with inhalational anesthetics will also be examined. Lastly, future research directions for volatile anesthetics as preconditioning agents in ischemic brain will be discussed.

\section{ANIMAL MODELS}

The following issues should be considered when developing or utilizing animal models to evaluate inhalational anesthetic preconditioning effects and mechanisms in ischemic brain: anesthetic agent and dose; ischemic model; animal species; preconditioning length and frequency; interval between preconditioning and cerebral ischemia; and outcomes (Table 3). Current research has focused mostly on isoflurane (1\% to 2.25\%) [5-13] primarily due to availability, cost, and clinical relevance but also includes sevoflurane (2\% to $4 \%)[14,15]$, halothane (1\% to $2 \%$ ) [5,16] and xenon (70\%) [17] (Table 3). Several focal (1 to 2 hours transient middle cerebral artery occlusion, MCAO $[6-8,10,16] ; 6 \mathrm{~h}$ to 4 days permanent MCAO $[5,9])$ and global $(7$ to 8 minutes cardiac arrest $[11,14] ; 10$ minutes bilateral carotid artery occlusion + hypotension [15]; 1 to 2.5 hours hypoxia-ischemia [12,13,17]) stroke models have been used primarily in rodents (rats, mice) [5-10,12-17], with very few studies in nonrodent species $(\mathrm{dog})$ [11]. Preconditioning period length has ranged from 30 minutes to 4 hours while the frequency has varied from a single exposure to daily exposure up to 5 consecutive days (Table 3). The protective effects of inhalational anesthetic preconditioning have been observed when preconditioning occurs from 0 to 24 hours before cerebral ischemia (Table 3 ).

Histopathology and neurological function are the most commonly used endpoints for assessing the preconditioning effects of inhalational anesthetics in ischemic brain (Table 3). Outcomes have been measured from approximately 1 day to 3 months post-ischemia in preconditioned brains [5-17].

\section{INHALATIONAL ANETHESTIC PRECONDITIONING EFFECTS}

\section{Isoflurane}

Isoflurane has been the most extensively studied inhalational anesthetic brain conditioning agent. Isoflurane preconditioning before permanent or transient focal cerebral ischemia reduced brain injury in male rodents [5-9] but either worsened or had no effect on infarct volume in female mice [10]. In global ischemia, isoflurane pretreatment improved neurological deficit scores in female dogs [11]. Isoflurane preconditioning before hypoxia/ischemia also decreased preweaning mortalilty, attenuated neonatal rat brain cell loss and damage, and improved adult striatal function $[12,13]$. These studies suggest that isoflurane preconditioning can be neuroprotective, neutral, or detrimental depending on the experimental ischemic model.

\section{Sevoflurane}

Current research on sevoflurane preconditioning has been limited to global ischemic brain injury. In global cerebral ischemia, sevoflurane pretreatment diminished neuronal damage in male rats $[14,15]$. It is unknown if sevoflurane preconditioning could have neuroprotective effects in other types of brain ischemia. 
Halothane

Preconditioning with halothane before permanent or transient focal stroke reduced infarction volume in male rats $[5,16]$. However, the decreased availability of halothane and the accessibility of alternative volatile anesthetics with fewer systemic side effects make it unlikely that additional research evaluating halothane preconditioning will be pursued.

Xenon

Xenon, a chemical element (atomic number 54) and a noble gas, has only recently been investigated as a brain preconditioning agent. Xenon-induced preconditioning before hypoxiaischemia in neonatal rats decreased infarction size and improved neurological function [17]. Xenon's use clinically as an anesthetic or as a preconditioning agent is currently restricted by its high cost, limited availability, and lack of a delivery system with gas recycling capabilities.

\section{Summary}

Brain preconditioning with isoflurane, sevoflurane, halothane, and xenon has generally yielded neuroprotective effects in ischemic brain (Table 3).

\section{PRECONDITIONING MECHANISMS}

Anesthetic preconditioning mechanisms are likely to be complex and interdigitated. Molecular and cellular mechanisms of volatile anesthetic action may partly explain the preconditioning effects of these agents. However, there may be unique or common mechanisms underlying anesthetic preconditioning compared with other types of brain preconditioning. Table 4 lists candidate mechanisms based on research concerning volatile anesthetic and other types of preconditioning in ischemic brain and heart [1,18-22]. For the purposes of this review, only selected mechanisms with supporting in vivo and in vitro evidence will be discussed. Many of the other potential anesthetic preconditioning mechanisms have yet to be validated in vivo or remain speculative.

\section{ATP-Sensitive Potassium ( $\left.\mathrm{K}_{\mathrm{ATP}}\right)$ Channels}

Evidence from ischemic preconditioning models in heart indicates that opening of $\mathrm{K}_{\mathrm{ATP}}$ channels alters reactive oxygen species (ROS) production, diminishes intra-ischemic mitochondrial calcium accumulation, and enhances post-ischemic mitochondrial energy production [23]. Furthermore, one study examining isoflurane preconditioning mechanisms in ischemic rabbit myocardium suggests that opening of $\mathrm{K}_{\mathrm{ATP}}$ channels acts as a preconditioning trigger through ROS generation [24]. These proposed protective mechanisms for ischemic and anesthetic preconditioning in myocardial ischemia may apply to inhalational anesthetic preconditioning in ischemic brain since several studies utilizing $\mathrm{K}_{\mathrm{ATP}}$ channel blockers have shown attenuation of beneficial isoflurane and sevoflurane preconditioning effects in cerebral, cortical, and hippocampal ischemic and hypoxic models [8,25-27]. Interestingly, blocking $\mathrm{K}_{\mathrm{ATP}}$ channels had no effect on isoflurane preconditioning neuroprotection in ischemic cerebellar slices [28], suggesting that there may be regional variations in brain $\mathrm{K}_{\mathrm{ATP}}$ channel distribution and activation.

\section{Nitric Oxide (NO)}

Depending on the amount and production origin, NO can have favorable or damaging effects in ischemic brain [29]. Endothelial and inducible nitric oxide synthase (iNOS) have been implicated in protection induced by ischemic preconditioning in brain [30,31]. Two studies evaluating ischemic neuronal injury in rat imply that isoflurane preconditioning neuroprotection is iNOS-dependent [5,12]. Unfortunately, little is known about the role of endothelial and neuronal NOS in an ischemic brain preconditioned with volatile anesthetics as 
well as the progression of NOS isoform induction and NO production for different inhalational anesthetics over time.

\section{Akt Activation}

Akt is a serine-threonine kinase whose activation via phosphorylation can control the balance between survival and death signaling in brain [32]. Several laboratories have shown that nonanesthetic, neuroprotective forms of brain preconditioning enhance Akt activation after cerebral ischemia in male and neonatal animals [31,33-36]. Only one study in a male mouse model of isoflurane preconditioning has shown that anesthetic preconditioning can induce brain Akt activation before ischemic injury occurs, potentially altering ischemic sensitivity, and that the neuroprotection from anesthetic preconditioning in ischemic brain is Akt isoform (Akt1)dependent [10].

\section{GENDER AND AGE EFFECTS ON PRECONDITIONING}

Women may have a greater perioperative stroke risk than men [37-39]. A recent review of randomized and non-randomized trials evaluating gender and age and stroke risk following CEA concluded that operative stroke risk is increased in women independent of age [40]. While gender and age are known to alter experimental ischemic brain outcomes [41,42], few studies have examined gender and age in preconditioned brain exposed to ischemic and other types of brain injury.

Investigational studies examining anesthetic and other forms of preconditioning in ischemic brain have used primarily young male animals. However, several studies suggest that the brain preconditioning response differs between genders and age groups. For example, a study in isoflurane preconditioned mice subjected to transient focal stroke showed exacerbation of or no protection from ischemic injury in young and middle-aged females, respectively, but reduced ischemic injury in comparably aged males [10]. Studies on hypoxic tolerance of mouse hippocampal slices chemically preconditioned with 3-nitro-propionate suggest that hypoxic tolerance and preconditioning are gender-dependent and modulated by gender-specific mechanisms [43,44]. Unfortunately, two studies which evaluated anesthetic and ischemic preconditioning in young female dogs [11] and aged gerbils [45], respectively, did not utilize age-matched males for comparison of gender and age preconditioning effects in ischemic brain. Likewise, in several neonatal hypoxia-ischemia studies, less brain damage and improved function was seen in isoflurane and xenon preconditioned rats but these findings were not stratified by gender $[12,13,17]$.

These results suggest that gender and age may modify an injured brain's response to inhalational anesthetic preconditioning. However, the underlying mechanisms for gender and age differences in volatile anesthetic effects on perioperative stroke risk are unknown and offer potential factors for optimizing anesthetic management of patients undergoing procedures at risk for perioperative stroke.

\section{CONCLUSIONS}

Whether inhalational anesthetics offer perioperative ischemic brain protection and which agents are the best preconditioning agents remain open questions. Future research should focus on dose, timing, and duration of anesthetic preconditioning as well as the severity of ischemic brain injury on preconditioned brain outcomes. Studies concerning long-term consequences and volatile anesthetic preconditioning mechanisms in ischemic brain also need to be performed if we are to translate findings to human patients and improve the direction and design of future clinical trials. In addition to examining inhalational anesthetic- and species-specific effects, investigators should evaluate age-and gender-specific responses and mechanisms for 
experimental volatile anesthetic preconditioning outcomes. The role of inhalational anesthetics in the morbidity and mortality of human perioperative stroke is unclear because of limited clinical information on inhalational anesthetics, perioperative stroke risk and neurological outcomes for surgical procedures. More prospective, randomized clinical trials are needed that compare the long-term consequences of different volatile anesthetic agents on perioperative stroke and outcomes for at risk surgical procedures.

\section{Acknowledgements}

Portions of this article were presented at the $23^{\text {rd }}$ International Symposium on Cerebral Blood Flow, Metabolism and Function (Brain’07) in Osaka, Japan by Dr. Murphy in May 2007.

\section{References}

1. Kitano H, Kirsch JR, Hurn PD, Murphy SJ. Inhalational anesthetics as neuroprotectants or chemical preconditioning agents in ischemic brain. J Cereb Blood Flow Metab 2007;27:1108-1128. [PubMed: 17047683]

2. Allain R, Marone LK, Meltzer J, Jeyabalan G. Carotid endarterectomy. Int Anesthesiol Clin 2005;43:15-38. [PubMed: 15632515]

3. Wilson PV, Ammar AD. The incidence of ischemic stroke versus intracerebral hemorrhage after carotid endarterectomy: a review of 2452 cases. Ann Vasc Surg 2005;19:1-4. [PubMed: 15714359]

4. Ferguson GG, Eliasziw M, Barr HWK, Clagett GP, Barnes RW, Wallace MC, Taylor DW, Haynes RB, Finan JW, Hachinski VC, Barnett HJM. The North American Symptomatic Carotid Endarterectomy Trial: surgical results in 1415 patients. Stroke 1999;30:1751-1758. [PubMed: 10471419]

5. Kapinya KJ, Lowl D, Futterer C, Maurer M, Waschke KF, Isaev NK, Dirnagl U. Tolerance against ischemic neuronal injury can be induced by volatile anesthetics and is inducible NO synthase dependent. Stroke 2002;33:1889-1898. [PubMed: 12105371]

6. Kapinya KJ, Prass K, Dirnagl U. Isoflurane induced prolonged protection against cerebral ischemia in mice: a redox sensitive mechanism? NeuroReport 2002;13:1431-1435. [PubMed: 12167768]

7•. Liu Y, Xiong L, Chen S, Wang Q. Isoflurane tolerance against focal cerebral ischemia is attenuated by adenosine $A_{1}$ receptor antagonists. Can J Anaesth 2006;53:194-2001. [PubMed: 16434762]The authors demonstrate that isoflurane-induced tolerance in ischemic rat brain may depend on adenosine $A_{1}$ receptor activation. The results of this study suggest that selective adenosine $A 1$ receptor agonists may be potentially useful as neuroprotective agents

8. Xiong L, Zheng Y, Wu M, Hou L, Zhu Z, Zhang X, Lu Z. Preconditioning with isoflurane produces dose-dependent neuroprotection via activation of adenosine triphosphate-regulated potassium channels after focal cerebral ischemia in rats. Anesth Analg 2003;96:233-237. [PubMed: 12505958]

9. Zheng S, Zuo Z. Isoflurane preconditioning induces neuroprotection against ischemia via activation of P38 mitogen-activated protein kinases. Mol Pharmacol 2004;65:1172-1180. [PubMed: 15102945]

10••. Kitano H, Young JM, Cheng J, Wang L, Hurn PD, Murphy SJ. Gender-specific response to isoflurane preconditioning in focal cerebral ischemia. J Cereb Blood Flow Metab 2007;27:13771386. [PubMed: 17264860]The authors observed that isoflurane preconditioning in ischemic mouse brain is only protective in males, that the sex-specific responses to isoflurane preconditioning are mediated through differences in Akt activation, and that male-specific neuroprotection from isoflurane preconditioning is Akt1-dependent. This is the first study to suggest that there is a divergence in isoflurane preconditioning-induced neuroprotective mechanisms in male versus female ischemia.

11. Blanck TJ, Haile M, Xu F, Zhang J, Heerdt P, Veselis RA, Beckman J, Kang R, Adamo A, Hemmings $\mathrm{H}$. Isoflurane pretreatment ameliorates postischemic neurologic dysfunction and preserves hippocampal $\mathrm{Ca}^{2+} /$ calmodulin-dependent protein kinase in a canine cardiac arrest model. Anesthesiology 2000;93:1285-1293. [PubMed: 11046218]

12. Zhao P, Zuo Z. Isoflurane preconditioning induces neuroprotection that is inducible nitric oxide synthase-dependent in neonatal rats. Anesthesiology 2004;101:695-702. [PubMed: 15329594] 
13••. McAuliffe JJ, Joseph B, Vorhees CV. Isoflurane-delayed preconditioning reduces immediate mortality and improves striatal function in adult mice after neonatal hypoxia-ischemia. Anesth Analg 2007;104:1066-1077. [PubMed: 17456654]The authors showed that isoflurane preconditioning 24 hours before severe neonatal hypoxia-ischemia in rats decreased preweaning mortality and improved adult striatal function. This study is the first demonstration of a long-term neuroprotective effect from isoflurane preconditioning in hypoxic-ischemic neonatal brain.

14••. Payne RS, Akca O, Roewer N, Schurr A, Kehl F. Sevoflurane-induced preconditioning protects against cerebral ischemic neuronal damage in rats. Brain Res 2005;1034:147-152. [PubMed: 15713266]The authors observed that a $30 \mathrm{~min}$ exposure to isoflurane 15 minutes before global ischemia or 30 minutes of isoflurane anesthesia daily for 4 consecutive days 24 hours before global ischemia reduced neuronal damage 7 days following ischemic injury. This is the first study to show in vivo neuroprotection with sevoflurane preconditioning in ischemic brain.

15•. Wang J, Lei B, Popp S, Meng F, Cottrell JE, Kass IS. Sevoflurane immediate preconditioning alters hypoxic membrane potential changes in rat hippocampal slices and improves recovery of CA1 pyramidal cells after hypoxia and global cerebral ischemia. Neuroscience 2007;145:1097-1107. [PubMed: 17291693]The authors demonstrated that sevoflurane preconditioning may protect rat neurons from global ischemic brain injury by attenuating electrophysiological changes during hypoxia. This study suggests that an anesthetic's metabotropic, rather than ionotropic, effects on cellular mechanisms may be more important for anesthetic preconditioning-induced neuroprotection.

16. Bhardwaj A, Castro AF III, Alkayed NJ, Hurn PD, Kirsch JR. Anesthetic choice of halothane versus propofol: impact on experimental perioperative stroke. Stroke 2001;32:1920-1925. [PubMed: 11486126]

17•. Ma D, Hossain M, Pettet GKJ, Luo Y, Lim T, Akimov S, Sanders RD, Franks NP, Maze M. Xenon preconditioning reduces brain damage from neonatal asphyxia in rats. J Cereb Blood Flow Metab 2006;26:199-208. [PubMed: 16034370]Preconditioning with xenon reduced infarction size 4 days following neonatal hypoxia-ischemia and improved neurological function 30 days after brain injury. This study suggests that xenon's preconditioning effect may be mediated through increased pCREBregulated synthesis of proteins that promote neuronal survival.

18•. Zuo Z, Wang Y, Huang Y. Isoflurane preconditioning protects human neuroblastoma SH-SY5Y cells against in vitro simulated ischemia-reperfusion through the activation of extracellular signalregulated kinases pathway. Eur J Pharmacol 2006;542:84-91. [PubMed: 16806162]Using human neuroblastoma SH-SY5Y cells and an in vitro ischemia model, the authors demonstrate that isoflurane preconditioning-induced protection involves the extracellular signal-regulated kinase (ERK)/early growth response gene 1 (Egr-1)/Bcl-2 pathway. This signaling pathway has been previously implicated in ischemic preconditioning-induced neuroprotection, suggesting common pathways for different types of brain preconditioning.

19. Clarkson AN. Anesthetic-mediated protection/preconditioning during cerebral ischemia. Life Sci 2007;80:1157-1175. [PubMed: 17258776]

20. Steiger HJ, Hanggi D. Ischaemic preconditioning of the brain, mechanisms and applications. Acta Neurochir (Wein) 2007;149:1-10. [PubMed: 17151832]

21. Perez-Pinzon MA. Mechanisms of neuroprotection during ischemic preconditioning: lessons from anoxic tolerance. Comp Biochem Physiol A Mol Integr Physiol 2007;147:291-299. [PubMed: 17045830]

22. Pratt PF Jr, Wang C, Weihrauch D, Bienengraeber MW, Kersten JR, Pagel PS, Warltier DC. Cardioprotection by volatile anesthetics: new applications for old drugs? Curr Opin Anaesthesiol 2006;19:397-403. [PubMed: 16829721]

23. O'Rourke B. Evidence for mitochondrial $\mathrm{K}^{+}$channels and their role in cardioprotection. Circ Res 2004;94:420-432. [PubMed: 15001541]

24. Tanaka K, Weihrauch D, Ludwig LM, Kersten JR, Pagel PS, Warltier DC. Mitochondrial adenosine triphosphate-regulated potassium channel opening acts as a trigger for isoflurane-induced preconditioning by generating reactive oxygen species. Anesthesiology 2003;98:935-943. [PubMed: 12657856]

25•. Kaneko T, Yokoyama K, Makita K. Late preconditioning with isoflurane in cultured rat cortical neurones. Br J Anaesth 2005;95:662-668. [PubMed: 16143577]The authors showed that isoflurane 
induced late preconditioning in cultured rat cortical neurons subjected to oxygen-glucose deprivation and that this neuroprotective effect is mediated through mitochondrial $\mathrm{K}_{\mathrm{ATP}}$ channels and through induced upregulation of neuronal glutamate transporter EAAC1 expression. This study provides further evidence that $\mathrm{K}_{\mathrm{ATP}}$ channels may be involved in anesthetic preconditioning of the brain

26. Kehl F, Payne RS, Roewer N, Schurr A. Sevoflurane-induced preconditioning of rat brain in vitro and the role of $\mathrm{K}_{\mathrm{ATP}}$ channels. Brain Res 2004;1021:76-81. [PubMed: 15328034]

27•. Wang ZP, Zhang ZH, Zeng YM, Jiang S, Wang SQ, Wang S. Protective effect of sevoflurane preconditioning on oxygen-glucose deprivation injury in rat hippocampal slices: the role of mitochondrial K $\mathrm{ATP}_{\mathrm{T}}$ channels. Sheng Li Xue Bao 2006;58:201-206. [PubMed: 16786103]Using an oxygen-glucose deprivation model in rat hippocampal cells, the authors observed that sevoflurane preconditioning protected neurons from injury but that this protective effect required activation of mitochondrial $\mathrm{K}_{\mathrm{ATP}}$ channels. This is one of the first studies to evaluate morphological and electrophysiological outcomes in a neuronal model of anesthetic preconditioning.

28. Zheng S, Zuo Z. Isoflurane preconditioning reduces purkinje cell death in an in vitro model of rat cerebellar ischemia. Neuroscience 2003;118:99-106. [PubMed: 12676141]

29. Bhardwaj A, Alkayed NJ, Kirsch JR, Hurn PD. Mechanisms of ischemic brain damage. Curr Cardiol Rep 2003;5:160-167. [PubMed: 12583862]

30. Hashiguchi A, Yano S, Morioka M, Hamada J, Ushio Y, Takeuchi Y, Fukugnaga K. Up-regulation of endothelial nitric oxide synthase via phosphatidylinositol 3-kinase pathway contributes to ischemic tolerance in the CA1 subfield of gerbil hippocampus. J Cereb Blood Flow Metab 2004;24:271-279. [PubMed: 15091107]

31. Huang PL. Nitric oxide and cerebral ischemic preconditioning. Cell Calcium 2004;36:232-329.

32. Brunet A, Datta SR, Greenberg ME. Transcription-dependent and -independent control of neuronal survival by the PI3K-Akt signaling pathway. Curr Opin Neurobiol 2001;11:297-305. [PubMed: 11399427]

33. Garcia L, Burda J, Hrehorovska M, Burda R, Martin ME, Salinas M. Ischaemic preconditioning in the rat brain: effect on the activity of several initiation factors, Akt and extracellular signal-regulated protein kinase phosphorylation, and GRP78 and GADD34 expression. J Neurochem 2004;88:136147. [PubMed: 14675157]

34. Nakajima T, Iwabuchi S, Miyazaki H, Okuma Y, Kuwabara M, Nomura Y, Kawahara K. Preconditioning prevents ischemia-induced neuronal death through persistent Akt activation in the penumbra region of the rat brain. J Vet Med Sci 2004;66:521-527. [PubMed: 15187362]

35. Yano S, Morioka M, Fukunaga K, Kawano T, Hara T, Kai Y, Hamada J, Miyamoto E, Ushio Y. Activation of Akt/protein kinase B contributes to induction of ischemic tolerance in the CA1 subfield of gerbil hippocampus. J Cereb Blood Flow Metab 2001;21:351-360. [PubMed: 11323521]

36. Yin W, Signore AP, Iwai M, Cao G, Gao Y, Johnnides MJ, Hickey RW, Chen J. Preconditioning suppresses inflammation in neonatal hypoxic ischemia via Akt activation. Stroke 2007;38:10171024. [PubMed: 17272774]

37. Koch CG, Khandwala F, Cywinski JB, Ishwaran H, Estafanous FG, Loop FD, Blackstone EH. Healthrelated quality of life after coronary artery bypass grafting: a gender analysis using the Duke Activity Status Index. J Thorac Cardiovasc Surg 2004;128:284-295. [PubMed: 15282467]

38. Ozatik MA, Gol MK, Fansa I, Uncu H, Kucuker SA, Kucukaksu S, Bayazit M, Sener E, Tasdemir O. Risk factors for stroke following coronary artery bypass operations. J Card Surg 2005;20:52-57. [PubMed: 15673410]

39. Weise J, Kuschke S, Bahr M. Gender-specific risk of perioperative complications in carotid endarterectomy patients with contralateral carotid artery stenosis or occlusion. J Neurol 2004;251:838-844. [PubMed: 15258786]

40. Bond R, Rerkasem K, Cuffe R, Rothwell PM. A systematic review of the associations between age and sex and the operative risks of carotid endarterectomy. Cerebrovasc Dis 2005;20:69-77. [PubMed: 15976498]

41. Murphy SJ, McCullough LD, Smith JM. Stroke in the female: role of biological sex and estrogen. ILAR J 2004;45:147-159. [PubMed: 15111734] 
42. Schaller BJ. Influence of age on stroke and preconditioning-induced ischemic tolerance in the brain. Exp Neurol 2007;205:9-19. [PubMed: 16631743]

43. Kasischke K, Huber R, Li H, Timmler M, Riepe MW. Primary hypoxic tolerance and chemical preconditioning during estrus cycle in mice. Stroke 1999;30:1256-1262. [PubMed: 10356109]

44. Von Arnim CAF, Etrich SM, Timmler M, Riepe MW. Gender-dependent hypoxic tolerance medicated via gender-specific mechanisms. J Neurosci Res 2002;68:84-88. [PubMed: 11933052]

45. Dowden J, Corbett D. Ischemic preconditioning in 18- to 20-month old gerbils: long-term survival with functional outcome measures. Stroke 1999;30:1240-1246. [PubMed: 10356107]

46. Peart JN, Gross ER, Gross GJ. Opioid-induced preconditioning: recent advances and future perspectives. Vas Pharmacol 2005;42:211-218.

47. Brambrink AM, Noga H, Astheimer A, Heimann A, Kempski O. Pharmacological preconditioning in global cerebral ischemia. Acta Neurochir Suppl 2004;89:63-66. [PubMed: 15335102]

48. Rosenzweig HL, Minami M, Lessov NS, Coste SC, Stevens SL, Henshall DC, Meller R, Simon RP, Stenzel-Poore MP. Endotoxin preconditioning protects against the cytotoxic effects of TNF $\alpha$ after stroke: a novel role for TNF $\alpha$ in LPS-ischemic tolerance. J Cereb Blood Flow Metab. 28 February; 2007 10.1038/sj.jcbfm.9600464

49. Bigdeli MR, Hajizadeh S, Froozandeh M, Rasulian B, Heidarianpour A, Khoshbaten A. Prolonged and intermittent normobaric hyperoxia induce different degrees of ischemic tolerance in rat brain tissue. Brain Res 2007;1152:228-233. [PubMed: 17475225]

50. Ran R, Xu H, Lu A, Bernaudin M, Sharp FR. Hypoxia preconditioning in the brain. Dev Neurosci 2005;27:87-92. [PubMed: 16046841]

51. Xu H, Aibiki M, Nagoya J. Neuroprotective effects of hyperthermic preconditioning on infarct volume after middle cerebral artery occlusion in rats: role of adenosine receptors. Crit Care Med 2002;30:1126-1130. [PubMed: 12006813]

52. Nishio S, Chen ZF, Yunoki M, Toyoda T, Anzivino M, Lee KS. Hypothermia-induced ischemic tolerance. Ann N Y Acad Sci 1999;890:26-41. [PubMed: 10668411]

53. Borges K, Shaw R, Dingledine R. Gene expression changes after seizure preconditioning in the three major hippocampal cell layers. Neurobiol Dis 2007;26:66-77. [PubMed: 17239605] 


\section{Brain Preconditioning Stimuli}

\section{Table 1}

\begin{tabular}{|l|c|}
\hline Stimulus & References \\
\hline Analgesics & {$[46]$} \\
\hline Anesthesia & {$[1,19]$} \\
\hline Chemical/Pharmacological & {$[47]$} \\
\hline Endotoxins & {$[48]$} \\
\hline Hyperoxia & {$[49]$} \\
\hline Hypoxia & {$[43,44,50]$} \\
\hline Hyperthermia & {$[51]$} \\
\hline Hypothermia & {$[52]$} \\
\hline Ischemia & {$[20,21,42,45$} \\
\hline Seizures & {$[53]$} \\
\hline
\end{tabular}


Table 2

Formulae and structures of inhalational anesthetics used as preconditioning agents in ischemic brain

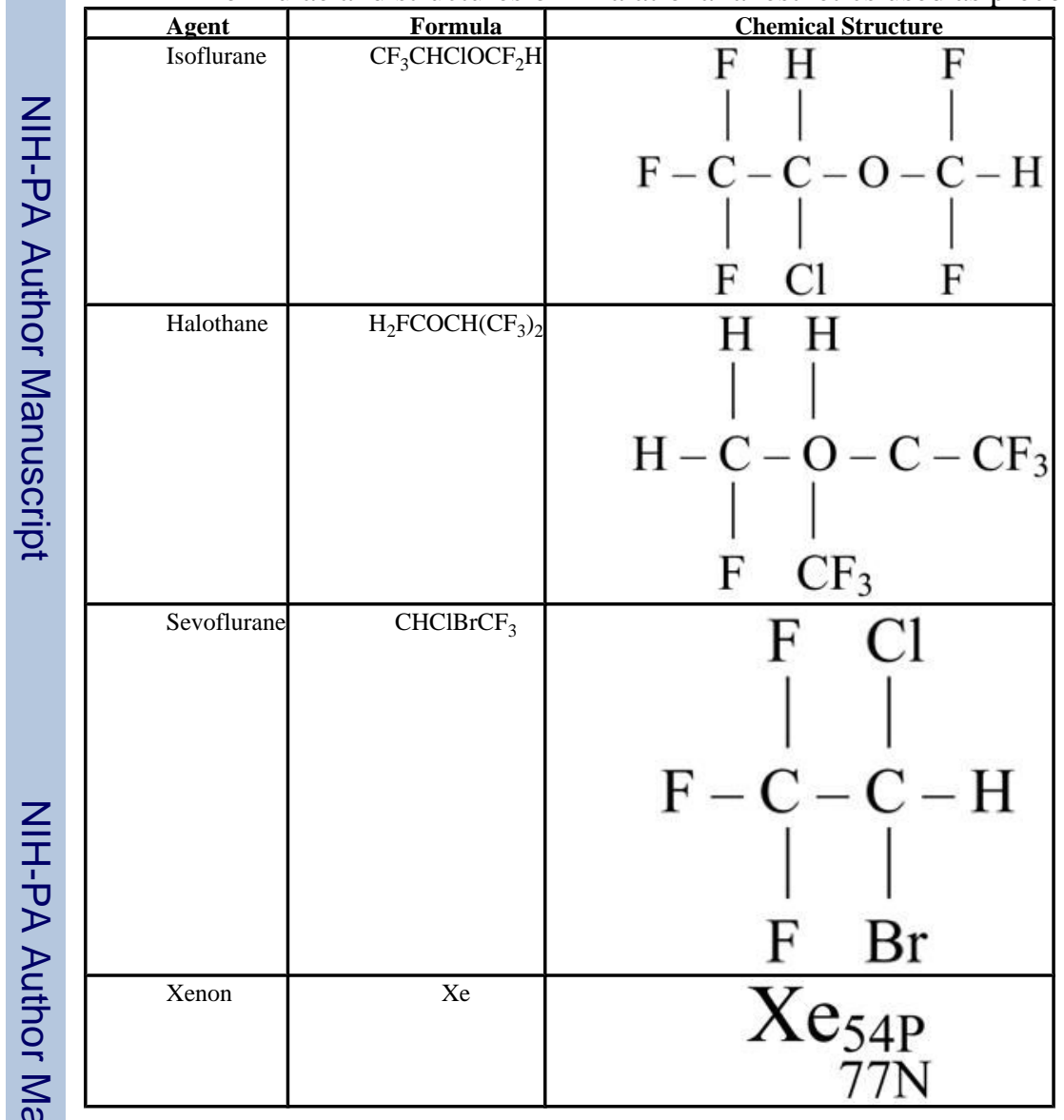


Wang et al.

Page 11

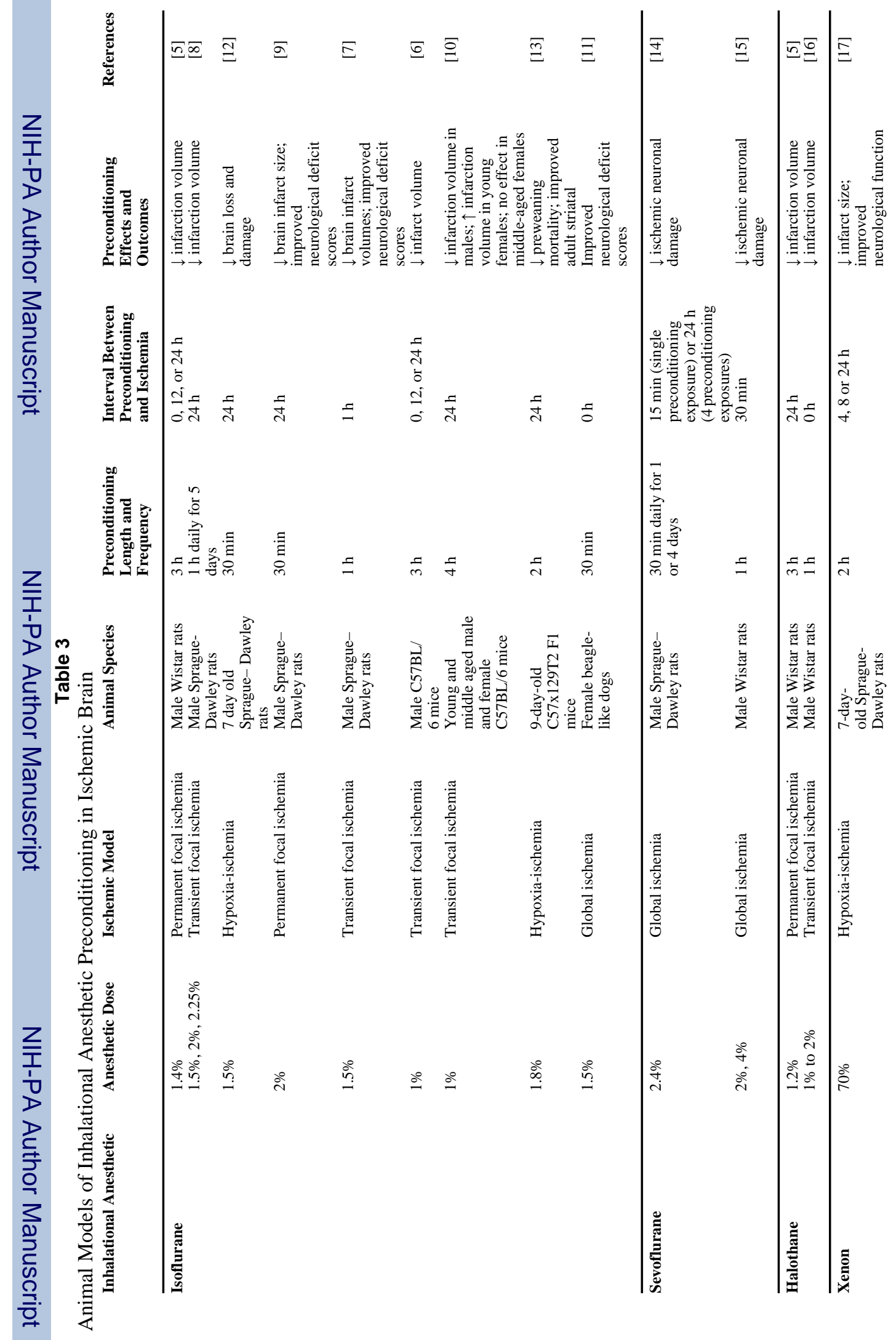

Curr Opin Pharmacol. Author manuscript; available in PMC 2009 February 1. 
Table 4

Candidate Inhalational Anesthetic Preconditioning Mechanisms Proposed Mechanism Akt activation

References

\begin{tabular}{|r|r|} 
ATP-sensitive potassium channels & {$[1,8,19,21-27]$} \\
\hline
\end{tabular}

\begin{tabular}{|c|c|} 
Nitric oxide and inducible nitric oxide synthase & {$[1,5,12,19,20,31]$} \\
\hline
\end{tabular}

\begin{tabular}{l|r} 
Inhibition of glutamate release & {$[1,19-21]$} \\
\hline
\end{tabular}

\begin{tabular}{|c|c} 
Calcium-dependent processes & {$[1,11]$} \\
\hline
\end{tabular}

\begin{tabular}{|c|c} 
Anti-apoptotic mechanisms & {$[1,17,19,22]$} \\
\hline
\end{tabular}

\begin{tabular}{|c|c|}
\hline Reactive oxygen species & {$[1,22]$} \\
\hline
\end{tabular}

\begin{tabular}{|l|l}
\hline Cerebral blood flow & {$[1]$} \\
\hline
\end{tabular}

Extracellular signal-regulated kinase (ERK)/Early growth response gene 1 (Egr-1)/Bcl-2 pathway $\quad[18,22]$

Adenosine $\mathrm{A}_{1}$ receptor activation

$[1,7,19-21]$

p38 mitogen-activated protein kinases

$[1,9]$ 